\title{
Attitude versus professioneel gedrag
}

K.P.M. van Spaendonck

\section{Samenvatting}

In het afgelopen decennium is attitude als eindterm van de medische opleiding betrekkelijk geruisloos terzijde geschoven ten gunste van professioneel gedrag. Dat is meer gebeurd uit overwegingen van beoordeling dan van onderwijs. Deze verschuiving blijkt bij nadere beschouwing verder te gaan dan alleen die van 'binnenkant' (attitude) naar 'buitenkant' (professioneel gedrag). Allereerst is er grote onhelderheid met betrekking tot inclusie en exclusie: wat moet nu wèl en wat niet tot professioneel gedrag gerekend worden. Met name de overlap met communicatieve vaardigheden is vaak zo groot dat het bestaansrecht van het onderscheid tussen de eindtermen 'vaardigheden' en 'professioneel gedrag' in het gedrang komt. Vervolgens blijkt professioneel gedrag exclusief gerelateerd te worden aan de waarden en normen van de beroepsgroep, waarbij het handelend subject met zijn eigen opvattingen over de professie en zijn eigen gedragsrepertoire uit het zicht verdwijnt. Tenslotte is niet duidelijk of en in hoeverre professioneel gedrag van de arts zich onderscheidt van dat van andere beroepen en wat daarvan de onderwijskundige consequenties zijn. (Spaendonck KPM van. Attitude versus professioneel gedrag. Tijdschrift voor Medisch Onderwijs 2006;25(6):285-290.)

\section{Inleiding}

In het Raamplan 1994 artsopleiding werden de eindtermen van de artsopleiding beschreven in termen van kennis, vaardigheden en attitudes. ${ }^{1}$ De term 'attitude' is afkomstig uit de sociale psychologie en wordt gedefinieerd als een complex van emoties en cognities waarvan is aangetoond dat het een substantiële voorspeller is van gedrag. ${ }^{2}$ Een alleszins relevant concept voor de medische professie, maar tevens nogal abstract en moeilijk te operationaliseren. Problemen rezen terstond, zodra gepoogd werd dit concept didactisch vorm te geven. Bestaat er wel zoiets als een eenduidig correcte beroepsattitude? Verwerft een student zich attitudes door instructies van een docent, of betreft het hier veeleer een ontwikkelingsproces? In 1995 verscheen er in het toenmalige Bulletin Medisch Onderwijs een artikel waarin werd gepoogd attitudeonderwijs simpel en concreet gestalte te geven, ${ }^{3}$ drie jaar later gevolgd door een themanummer over dit onderwerp, waaruit bleek dat er in Nederland sterk uiteenlopende visies waren op attitude en het onderwijs erin. ${ }^{4}$ Wat is sedertdien gebeurd in dit domein?

\section{Van attitude naar professioneel gedrag}

In de herziene versie van het Raamplan 1994 artsopleiding uit 2001 blijkt de eindterm 'attitude' te zijn vervangen door 'professioneel gedrag'. ${ }^{5}$ De toelichting op deze allesbehalve marginale wijziging is summier. In een voetnoot op p. 20 staat te lezen: "aan de term 'professioneel gedrag' is de voorkeur gegeven boven het in Raamplan 1994 gehanteerde begrip 'attitude'. Het eerstgenoemde begrip benadrukt dat het in deze context alléén gaat om het uitwendig waarneembare gedragsaspect van de beroepsattitude."

Kennis, vaardigheden en professioneel gedrag hebben in het raamplan betrek- 
king op vier rubrieken. Als we ervan uitgaan dat met 'blijk geven van' een manifestatie van professioneel gedrag wordt aangeduid, dan manifesteert professioneel gedrag zich als volgt:

- Medische aspecten eenmaal: "De arts geeft blijk van: aandacht voor de betekenis van gezochte gegevens en toevalsbevindingen."

- Wetenschappelijke aspecten tweemaal: "De arts geeft blijk van een kritische houding ten opzichte van de wetenschappelijke kennis waarop het medisch handelen is gebaseerd" en "De arts geeft blijk van besef dat na de artsopleiding verdere na- en bijscholing nodig is."

- Aspecten in relatie tot de maatschappij en het gezondheidszorgsysteem eenmaal: "De arts geeft blijk van: gevoel voor uiteenlopende morele opvattingen en respect voor andere meningen en opvattingen."

- Persoonlijke aspecten 32 maal!

Allereerst, er valt over te twisten of blijk geven van aandacht voor betekenis, een kritische houding en van besef en gevoel en respect als uitwendig waarneembare gedragsaspecten te kwalificeren valt. De intrapsychische component is in deze formuleringen steeds overduidelijk aanwezig.

Vervolgens is duidelijk dat professioneel gedrag vooral te maken heeft met persoonlijke aspecten die in drie subrubrieken zijn onderverdeeld: de arts-patiënt relatie, persoonlijk functioneren en de wederzijdse beïnvloeding van werk en privéleven. Ook hier roept de formulering van items vaak de vraag op of het gaat om uitwendig waarneembaar gedrag. Zo staat er onder meer: "De arts geeft blijk van besef dat voor het functioneren als arts vereist is, dat hij:

- kan omgaan met onzekerheid;

- kan omgaan met acute situaties;
- kan omgaan met stress;

- verantwoordelijkheid kan dragen."

Blijk geven van besef is iets anders dan zich conform dat besef te gedragen. Ook het kunnen omgaan zegt vooralsnog niets meer dan dat iemand in staat is tot bepaald gedrag (hetgeen overigens een vaardigheid is), maar niet dat iemand dat gedrag ook feitelijk laat zien.

De formulering: “(...) besef dat hij (...) kan omgaan” suggereert veeleer cognities omtrent bepaald gedrag dan het concrete gedrag zelf en laat om die reden nogal wat vrijblijvendheid toe.

Samenvattend: op de in het Raamplan 2001 artsopleiding gemaakte keuze voor professioneel gedrag als louter het uitwendig waarneembare gedragsaspect van de beroepsattitude valt nogal wat af te dingen: de manifestaties van professioneel gedrag zijn in het raamplan niet als feitelijk, concreet gedrag geformuleerd, maar bevatten nogal wat elementen van intrapsychische aard.

\section{Professioneel gedrag: in- en exclusie}

Wat moet nu wèl en wat niet tot professioneel gedrag gerekend worden? In het ICRA-rapport, dat overigens nog over attitude spreekt, wordt het boven vermelde onderscheid tussen 'kunnen' en 'doen' nog helder neergezet. ${ }^{6}$ Op p. 27 staat te lezen: 'De termen 'competentie' en 'performance' zijn niet identiek: de eerste geeft aan waartoe een persoon in staat is, het tweede duidt op zijn feitelijke functioneren, hoe hij de verkregen competentie in de praktijk toepast."

In het erop volgende rapport getiteld Beoordeling van de algemene klinische competentie, een advies van de Werkgroep Consilium Abeundi van het Disciplineorgaan Medische Wetenschappen, wordt ervoor gekozen om zich te bepalen tot de 'buitenkant' van attitude, verder aangeduid als 'professioneel gedrag'. ${ }^{7}$ De werk- 
groep neemt het verschil tussen kunnen (competentie) en doen (performance) niet over, maar onderscheidt aan de algemene klinische competentie verschillende vaardigheidscomponenten: enerzijds cognitieve, perceptuele en psychomotorische vaardigheden, samengevat in de term professioneel handelen en anderzijds sociale en communicatieve vaardigheden, samengevat in de term professioneel gedrag, waarin de normen en waarden van de beroepsuitoefening uitdrukking krijgen. Professioneel gedrag wordt dus beschouwd als een groep vaardigheden, waarmee het op gespannen voet staat met het Raamplan 2001 artsopleiding dat vaardigheden en professioneel gedrag als aparte eindtermen beschouwt. De begripsvervaging neemt toe. Er zijn dan in Nederland diverse beoordelingsformulieren voor professioneel gedrag in omloop. Wanneer men die naast elkaar legt, dan laat de helderheid met betrekking tot inclusie en exclusie nogal wat te wensen over. Aan de Erasmus Universiteit Rotterdam (EUR) rekent men bijvoorbeeld beheersing van de Nederlandse taal tot professioneel gedrag, aan het Amsterdams Medisch Centrum (AMC) weer het structureren van het gesprek. Maar gaat het hier nu om vaardigheden of om professioneel gedrag? Wanneer men de uitgebreide toelichting van de Attitude- en communicatie Schaal van het AMC doorleest, rijst de vraag wat er eigenlijk niet tot professioneel gedrag gerekend moet worden. Als de overlap met vooral vaardigheden inderdaad zo groot is, wat is dan nog het bestaansrecht van de eindterm professioneel gedrag? Het is zelf aanvechtbaar of er zoiets als professioneel gedrag sec bestaat. Veeleer lijkt het te gaan om een kwaliteitsaspect van het medisch handelen. Niettemin pleit er veel voor om professioneel gedrag en vaardigheden te onderscheiden: medische - inclusief communi- catieve - vaardigheden vormen als het ware de gereedschapskist van de arts. Het besluit om er zich van te bedienen en de wijze waarop de arts er zich van bedient liggen binnen het domein van het professioneel gedrag.

Met de introductie van de term professioneel gedrag blijkt de deur te zijn opengezet naar grensvervaging tussen competentie en performance en naar een grote overlap met (communicatieve) vaardigheden die men in tal van publicaties tegenkomt, en waar men met het handhaven van attitude geen last van zou hebben gehad. Nochtans is de keuze voor professioneel gedrag juist om didactische redenen verantwoord: een correcte attitude garandeert geenszins dat de betrokkene zich daadwerkelijk conform die attitude zal gedragen. Daarvoor is attitude te vrijblijvend. Tevens doet zich bij attitude de grote bias voor van sociale wenselijkheid: de betrokkene geeft de docent/opleider alleen maar dat te horen wat deze graag wil horen. Deze twee didactische valkuilen vrijblijvendheid en sociale wenselijkheid zijn bij een keuze voor professioneel gedrag beter te vermijden.

\section{Professioneel gedrag tussen normen/waarden en het handelend subject}

De term professioneel gedrag is mede in het licht van het Raamplan 2001 artsopleiding interessant. Zo staat in het rapport Beoordeling van de Algemene Klinische Competentie: "Teneinde met name op het terrein van het persoonlijk functioneren verwarring te voorkomen met subjectieve, tot het privé-domein van studenten behorende aspecten, geeft de werkgroep er de voorkeur aan in dit verband te spreken van professioneel gedrag." De lezer zij eraan herinnerd dat in het Raamplan 2001 artsopleiding het overgrote deel van de items professioneel gedrag zijn ondergebracht 
in de rubriek 'persoonlijk functioneren'. Er valt ook best wat af te dingen op de voorgestane eliminatie van het privé-domein van de student. Is bijvoorbeeld de gezondheidszorg beter uit met een student die bij zijn ouders blijft wonen om uitsluitend in de boeken te vossen dan met een student die midden in het leven staat? En is het aannemelijk dat zulke leefstijlen los staan van professioneel gedrag?

Het Eindrapport van het Projectteam Consilium Abeundi definieert professioneel gedrag als 'observeerbaar gedrag waarin de normen en waarden van de beroepsgroep zichtbaar zijn.' ${ }^{8}$ In deze definitie is degene die zich gedraagt, hierna aan te duiden als het handelend subject, als zodanig verdwenen, terwijl die in het concept attitude juist centraal staat. Daarmee gaat de vervanging van attitude door professioneel gedrag conceptueel beduidend verder dan alleen die van binnenkant naar buitenkant. Dat heeft grote consequenties voor het onderwijs in deze materie.

Deze definitie suggereert dat correct professioneel gedrag rechtstreeks en eenduidig is af te leiden van de normen en waarden van de beroepsgroep. Als het inderdaad zo is, dan zou onderwijs in professioneel gedrag zich tot simpele gedragsinstructie kunnen beperken en de beoordeling tot observatie of die gedragsinstructie wordt geïmplementeerd. De normen en waarden laten echter ruimte voor een grote variatie aan gedragsmanifestaties en deze ruimte wordt als het ware ingenomen door het handelend subject. Een extravert, joviaal en een terughoudend, stil persoonlijkheidstype kunnen beide correct professioneel gedrag laten zien, dat toch heel verschillend is. Professioneel gedrag is dus gerelateerd aan het individueel gedragsrepertoire van het handelend subject. Bovendien is het aannemelijk dat professioneel gedrag niet uitsluitend normen en waarden van de beroepsgroep weerspiegelt, maar ook opvattingen, zowel van de beroepsgroep als van het handelend subject, over de medische professie waarvan normen en waarden weliswaar deel uitmaken, maar niet uitsluitend. Een enkel voorbeeld uit de concrete onderwijspraktijk ter adstructie:

Een arts-assistent: 'Als ik een patiënt een keer goed heb uitgelegd waarom hij er een gezondere leefstijl op na moet houden en de volgende keer blijkt hij dat advies aan zijn laars gelapt te hebben, dan houdt het voor mij op. Dat is dan verder zijn verantwoordelijkheid.'

Uit dit citaat spreekt de opvatting dat verantwoordelijkheid van de arts voor het realiseren van therapietrouw ophoudt na eenmalige adequate voorlichting en die opvatting is medebepalend voor zijn feitelijke gedrag.

Het loutere feit dat in het Raamplan 2001 artsopleiding het overgrote deel van items die gerelateerd zijn aan professioneel gedrag worden ondergebracht in de rubriek 'persoonlijk aspecten' wijst er al op dat we het handelend subject beter niet buiten beschouwing kunnen laten als we professioneel gedrag willen definiëren.

\section{Professioneel gedrag versus profes- sioneel gedrag van de arts}

Een kwestie die men in voornoemde rapporten vergeefs zal zoeken is de volgende: onderscheidt professioneel gedrag van de arts zich eigenlijk wel van professioneel gedrag van andere beroepen? Als men nagaat in hoeverre bovenstaande definitie ook op andere beroepen van toepassing kan zijn, dan is het antwoord bevestigend: niet alleen voor andere beroepen in de gezondheidszorg, maar ook voor alle beroepen, waarin men met andere mensen te maken krijgt zoals de advocaat of de leerkracht, is deze definitie onverkort te handhaven. Waarom maken vooral op- 
leidingen in de geneeskunde zich dan zo druk over professioneel gedrag? Zijn er gedragsaspecten in de medische professie aan te wijzen die de prominente plaats van professioneel gedrag in de eindtermen van de opleiding rechtvaardigen? Deze vraag moet bevestigend beantwoord worden, maar niet in absolute zin. Alle professies vragen in zekere zin om professioneel gedrag en daarin is de medische professie niet van andere te onderscheiden. Het onderscheid komt pas naar voren als we degene erbij betrekken om wie het uiteindelijk te doen is. Voor de advocaat is dat de cliënt, voor de leerkracht de leerling en voor de arts de patiënt. De specifieke eigenschappen van de arts-patiënt relatie, waarin specifieke vormen van vertrouwelijkheid, afhankelijkheid, intimiteit en lichamelijk contact een kardinale rol spelen, maken het professioneel gedrag van de arts specifiek. Naarmate de studie voortschrijdt en het welzijn van de patiënt meer in het vizier komt, dienen de meer specifieke aspecten van professioneel gedrag van de arts, waarin dat zich onderscheidt van dat van andere beroepen, aandacht te krijgen.

Bovenstaande overwegingen rond het concept 'professioneel gedrag' heeft de Nijmeegse projectgroep dienaangaande ertoe gebracht een strakkere, specifiekere definitie dan de gangbare voor te stellen: "Professioneel gedrag van de arts is het feitelijke gedrag van de individuele arts voor zover dat direct of indirect betrekking heeft op het welzijn van de patiënt. Dit gedrag is een kwaliteitsaspect van het medische handelen, weerspiegelt als zodanig de opvattingen van de beroepsgroep alsmede van de betrokken arts en is geïntegreerd in diens individuele gedragsrepertoire." 9

\section{Conclusies}

De betrekkelijk geruisloos verlopen vervanging van attitude door professioneel gedrag is voortgekomen uit overwegingen van beoordeling en niet van onderwijs. De implicaties van deze vervanging zijn beduidend groter dan op het eerste oog het geval lijkt: louter een verschuiving van binnenkant naar buitenkant. Zo is het handelend subject - bij de definitie van attitude nog centraal - in de omschrijving van professioneel gedrag nagenoeg uit het zicht verdwenen.

Het schort het concept 'professioneel gedrag' in menig opzicht aan helderheid: het concept is onvoldoende afgegrensd ten opzichte van attitude, ethiek en communicatieve vaardigheden. Het onderscheid tussen competence en performance is meestal zoek.

De kwestie of er wel zoiets als professioneel gedrag van de arts bestaat, wordt eigenlijk niet eens gesteld. Wanneer men de gangbare rubriceringen en beoordelingsinstrumenten erop naslaat, is het onderscheid tussen professioneel gedrag in het algemeen en dat van de arts flinterdun. Het specifieke van het professioneel gedrag van de arts moet gezocht worden in gedragsaspecten die voortvloeien uit het primaat van de professie, zijnde: staan voor het welzijn van de patiënt. Aspecten van professioneel gedrag die te maken hebben met wetenschappelijkheid, collegialiteit, enzovoorts, zijn in geval van de arts een afgeleide van het staan voor het welzijn van de patiënt.

Het concept 'professioneel gedrag' is ondanks deze beperkingen een alleszins bruikbaar concept. Professioneel gedrag is aanzienlijk toegankelijker voor beoordeling dan attitude. Bovendien brengt het op het niveau van onderwijs grote voordelen met zich mee in het ondervangen van vrijblijvendheid en sociale wenselijkheid.

Het verdient aanbeveling beoordelingsinstrumenten voor professioneel gedrag te herzien in het licht van de thans gangbare rubricering. $8-10$ 


\section{Literatuur}

1. Metz JCM, Pels Rijcken-van Erp Taalman Kip EH, Brand-Valkenburg BWM van den. Raamplan 1994 artsopleiding: eindtermen van de artsopleiding. Nijmegen: Universitair Publicatiebureau Katholieke Universiteit Nijmegen; 1994.

2. Brehm SS, Kassin SM, Fein S. Social psychology. Boston, New York: Houghton Mifflin; 2002.

3. Spaendonck KPM van. Attitude-onderwijs in zakformaat. Bulletin Medisch Onderwijs 1995;14:6975.

4. Selleger VJ, Batenburg V, Spaendonck KPM van. Het binnenste buiten: attitude-onderwijs in de artsopleiding. Interfacultaire Werkgroep Praktisch Medisch Onderwijs van de Nederlandse Vereniging voor Medisch Onderwijs; 1996.

5. Metz JCM, Verbeek-Weel AMM, Huisjes HJ. Raamplan 2001 artsopleiding. Bijgestelde eindtermen van de artsopleiding. Nijmegen: Mediagroep; 2001.

6. Metz JCM, Stoelinga GBA, Vleuten CPM van der, Jacobs JCG, editors. Het artsexamen: voorstellen voor landelijke richtlijnen. Eindrapport van de Interfacultaire Commissie Richtlijnen Artsexamen (ICRA). Nijmegen: Universitair Publicatiebureau Katholieke Universiteit Nijmegen; 1996.

7. Hokwerda O, editor. Beoordeling van de algemene klinische competentie: advies van de werkgroep Consilium abeundi van het Disciplineorgaan Medische Wetenschappen (Vereniging van Samenwerkende Nederlandse Universiteiten). Utrecht: VSNU; 2000.
8. Projectteam Consilium Abeundi. Professioneel gedrag: onderwijs, toetsing, begeleiding en regelgeving. Eindrapport van het Projectteam Consilium Abeundi. Utrecht: Disciplineorgaan Medische wetenschappen van de Vereniging van Samenwerkende Nederlandse Universiteiten; 2002.

9. Spaendonck KPM van, Timmermans L, Thoben A, Postma C. Professioneel gedrag. Begripsbepaling, onderwijs en toetsing. Nijmegen: Onderwijsinstituut UMC St. Radboud; 2006.

10. Spaendonck KPM van, Luijk SJ van. Professioneel gedrag. In: Kaptein AA, Erdman RA, Prins JB, Wiel HBM van de, editors. Medische Psychologie. Houten: Bohn Stafleu van Loghum; 2006. p. 219-26.

De auteur:

Dr. K.P.M. van Spaendonck is universitair hoofddocent medische psychologie aan het UMC St. Radboud te Nijmegen.

Correspondentieadres:

Dr. K.P.M. van Spaendonck, UMC St. Radboud, 840 afd. Medische Psychologie, Postbus 9101, 6500 HB Nijmegen, KPMvanSpaendonck@gmail.com.

Belangenconflict: geen gemeld.

Financiële ondersteuning: geen gemeld.

\section{Summary}

The past decade has seen the abandonment of attitude in favour of professional behaviour as one of the final objectives of medical education. This change was inspired more by considerations related to assessment than by educational motivations. A closer look reveals that this shift has more far reaching consequences than would be expected from a mere change from 'inside' to 'outside'. In the first place, it is not at all clear what is and what is not to be subsumed under the concept of professional behaviour. More specifically, the strong overlap between communication skills and professional behaviour makes one wonder whether a distinction between the two serves any useful purpose. Another concern is that the focus of professional behaviour has turned out to be exclusively on the profession's norms and values, whilst the acting individual with his or her personal ideas and behavioural repertoire is fading into the background. Finally, it is not at all clear whether and to what extent doctors' professional behaviour is essentially different from that of other professionals, and if so, what the educational consequences should be. (Van Spaendonck KPM. Attitude versus professional behaviour. Dutch Journal of Medical Education 2006;25(6):285-290.) 